\title{
A Segmental Approach with SWT Technique for Denoising the EOG Signal
}

\author{
Naga Rajesh \\ Department of Physics and Nanotechnology, Faculty of Engineering and Technology, SRM University, Kattankulathur, \\ Kancheepuram, Tamil Nadu 603203, India
}

Correspondence should be addressed to Naga Rajesh; nagarajesh9@yahoo.co.in

Received 26 September 2015; Revised 23 October 2015; Accepted 25 October 2015

Academic Editor: Aiguo Song

Copyright (C) 2015 Naga Rajesh. This is an open access article distributed under the Creative Commons Attribution License, which permits unrestricted use, distribution, and reproduction in any medium, provided the original work is properly cited.

The Electrooculogram (EOG) signal is often contaminated with artifacts and power-line while recording. It is very much essential to denoise the EOG signal for quality diagnosis. The present study deals with denoising of noisy EOG signals using Stationary Wavelet Transformation (SWT) technique by two different approaches, namely, increasing segments of the EOG signal and different equal segments of the EOG signal. For performing the segmental denoising analysis, an EOG signal is simulated and added with controlled noise powers of $5 \mathrm{~dB}, 10 \mathrm{~dB}, 15 \mathrm{~dB}, 20 \mathrm{~dB}$, and $25 \mathrm{~dB}$ so as to obtain five different noisy EOG signals. The results obtained after denoising them are extremely encouraging. Root Mean Square Error (RMSE) values between reference EOG signal and EOG signals with noise powers of $5 \mathrm{~dB}, 10 \mathrm{~dB}$, and $15 \mathrm{~dB}$ are very less when compared with $20 \mathrm{~dB}$ and $25 \mathrm{~dB}$ noise powers. The findings suggest that the SWT technique can be used to denoise the noisy EOG signal with optimum noise powers ranging from $5 \mathrm{~dB}$ to $15 \mathrm{~dB}$. This technique might be useful in quality diagnosis of various neurological or eye disorders.

\section{Introduction}

The electric field around the eye changes when it moves, producing an electrical signal known as Electrooculogram (EOG) signal. This is due to the formation of electric dipole, as the cornea and retina of the eye behave as positive and negative poles. In order to present an easy and accurate interpretation it is very much important to separate valid signal components from the noises caused by power-line interference and undesired artifacts [1]. To remove signal components from unwanted frequency ranges different types of digital filters are used. It is difficult to reduce artifacts caused by unexpected human behavior depending on the time, with fixed coefficients of the digital filters [2]. This problem can be overcome by adaptive filtering technique. The Recursive Least Squares (RLS) algorithm, whose convergence does not depend on the input signal, is the fastest of all conventional adaptive algorithms and it has been the best adaptive algorithm to denoise nonstationary signals like EOG, ECG, EMG, and so forth [3]. In analyzing the biomedical signals like EOG, wavelet transform has emerged as one of the excellent techniques. For better understanding of the signal behavior the wavelet transform is capable of transforming a time domain signal into frequency localization [4]. A wavelet is a small wave which is oscillatory to discriminate between different frequencies and contains both the analyzed shape and the window [5].

In this paper, by the method of simulation, the performance of SWT technique is analyzed by the calculation of Root Mean Square Error (RMSE) values. The technique is also compared with the RLS adaptive filter algorithm which was proven to be suitable adaptive filter algorithm for EOG signal processing [3]. Therefore, the results of the study are presented.

\section{SWT}

SWT applies high and low pass filters to the data at each level. It does not decimate and modify the filter at each level, by padding them with zeros. It is computationally more 


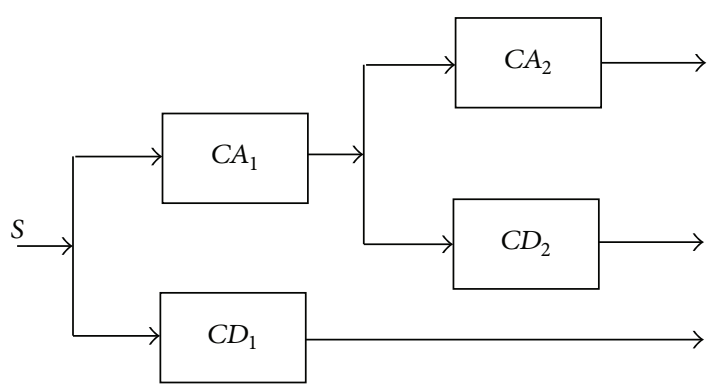

FIgURE 1: Wavelet decomposition scheme.

complex. The selection of subsets of the scales " $m$ " and positions " $n$ " of the mother wavelet $\psi(t)[6-8]$ is as follows:

$$
\psi_{m, n}(t)=2^{m / 2} \psi\left(2^{m} t-n\right) .
$$

Dyadic scales and positions ( $m$ and $n$ are integers) are based on powers of two. Wavelet for any function is built by dilation of function $\psi(t)$ with a coefficient $2^{m}$ (from (1)) resulting in the translated function interval on a grid proportional to $2^{-m}$. By correlating the original signal with wavelet function of different sizes, the details of the signal are obtained at several scales. This hierarchical scheme called multiresolution decomposition separates the signals into "approximations" and "details" at different scales. The SWT preserves the property that a translation of original signal does not necessarily imply a translation of the corresponding wavelet coefficient [9-12]. The decomposition scheme is shown in Figure 1.

\section{Adaptive Filter}

Adaptive filter has "self-regulation" and "tracking" capacities. Its design does not require the prior knowledge of signal and noise characteristics, as it observes the statistical properties of the existing signal and in normal operation the parameters are adjusted automatically.

The input signal $x(n)$ is applied to the adaptive filter so as to produce output signal $y(n)$. Error signal $e(n)$ is the difference of desired signal $d(n)$ and the filter output $y(n)$. Therefore, adaptive filter automatically carries on a design based on the characteristic of the input signal $x(n)$ and the desired signal $d(n)$. RLS adaptive algorithm was considered as adaptive algorithm in Figure 2 [13].

\section{RLS Algorithm}

The RLS adaptive filter employs the following algorithm for prediction.

Here $(n)=\left[\begin{array}{llll}x(n-1) & x(n-2) & \cdots & x(n-p)\end{array}\right]$ for an $M$ order adaptive filter and $X k=X(n)$ at $n=k$.

while |error| not less than a predefined $\varepsilon>0$

do begin

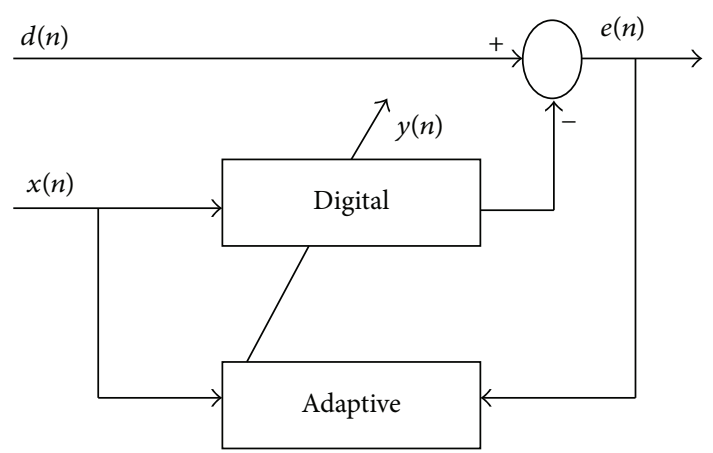

Figure 2: Principle of adaptive filter.

evaluate

$$
\begin{gathered}
\text { error } e(n)=d(n)-W \operatorname{Tn} X(n) \\
g(n)=(n-1) X *(n) \\
\{\lambda+X(n) P(n-1) X *(n)\}-1 \\
P(n)=\lambda-1(n-1)-g(n) X T(n) \lambda-1(n-1) \\
W n=W n-1+e(n) g(n)
\end{gathered}
$$

end While;

Here $P(n)$ is the inverse of the weighted autocorrelation matrix of $X k$ weighted by the forgetting factor $\lambda$.

That is, $P(n)=R x^{-1}(n)$, where

$$
R x(n)=\sum \lambda(n-i) X *(i) X T(i) .
$$

$d(n)$ is desired signal, $e(n)$ is error, and $W(n)$ is weight vector all at time sample $t=n$.

With $W 0=0, P(0)=\delta-1 I$, where $I$ is a $(M+1)(M+1)$ identity matrix and $\lambda$ is the forgetting factor which is equal to 0.99 [14].

\section{Methodology}

Figure 4(a) is an EOG signal comprising horizontal-vertical eye movements and blinks simulated and used as reference EOG signal throughout the analysis. The power of the reference EOG signal is found to be $44.11 \mathrm{~dB}$.

Five noisy EOG signals are simulated by adding controlled noises of powers $5 \mathrm{~dB}, 10 \mathrm{~dB}, 15 \mathrm{~dB}, 20 \mathrm{~dB}$, and $25 \mathrm{~dB}$, respectively, to the reference EOG signal. The SNRs of the respective five noisy EOG signals are $39.04 \mathrm{~dB}, 33.92 \mathrm{~dB}$, $29.02 \mathrm{~dB}, 24.12 \mathrm{~dB}$, and $19.01 \mathrm{~dB}$. The five noisy EOG signals are named as EOG5 dB, EOG10 dB, EOG15 dB, EOG20 dB, and EOG25 dB.

These noisy EOG signals are denoised using SWT technique. Bior 3.3 (Figure 3) wavelet is selected for the present analysis based on the promising results obtained in the previous published report [4].

The denoising analysis is performed by two methods:

(i) increasing segments (in steps of 512 samples) from 1 to 8192 samples of noisy EOG signal (1:512,1: $1024,1: 1536, \ldots)$; 

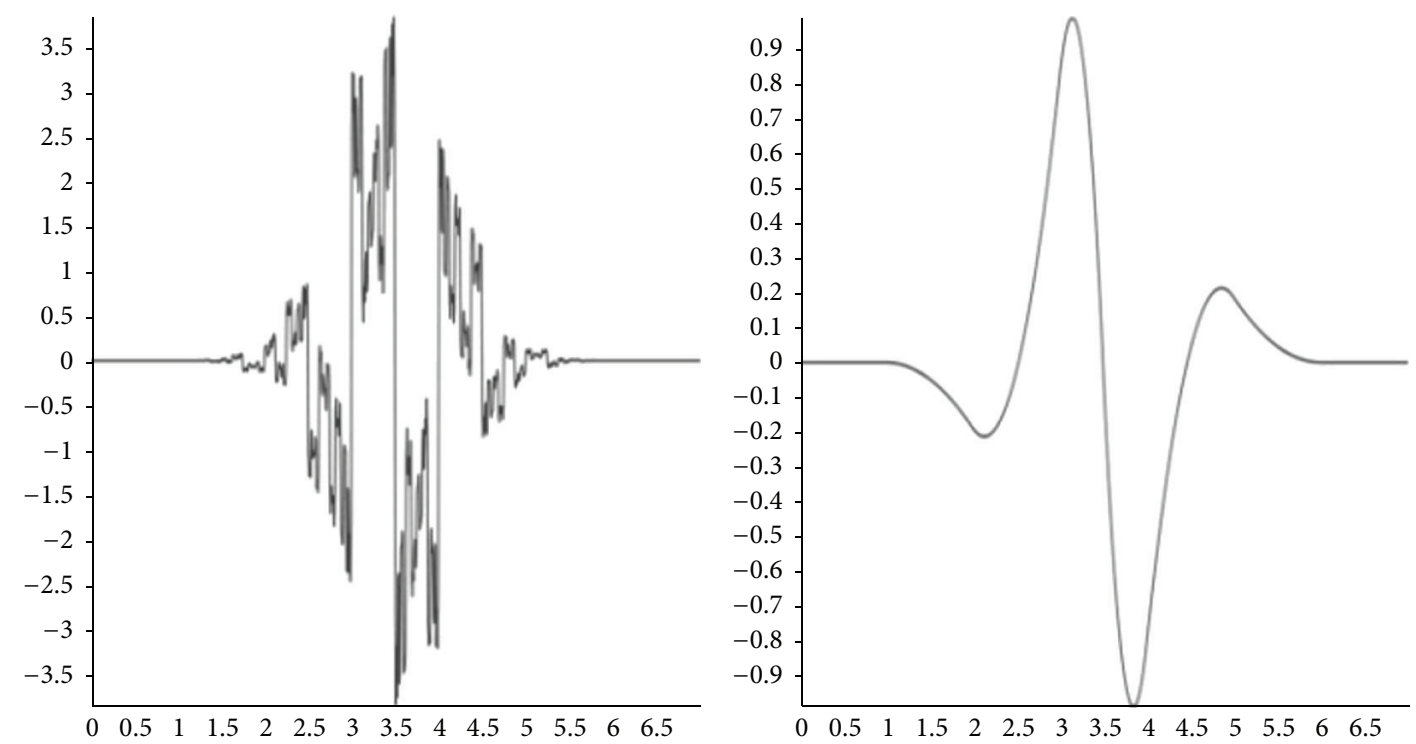

Figure 3: Biorthogonal 3.3 wavelet.

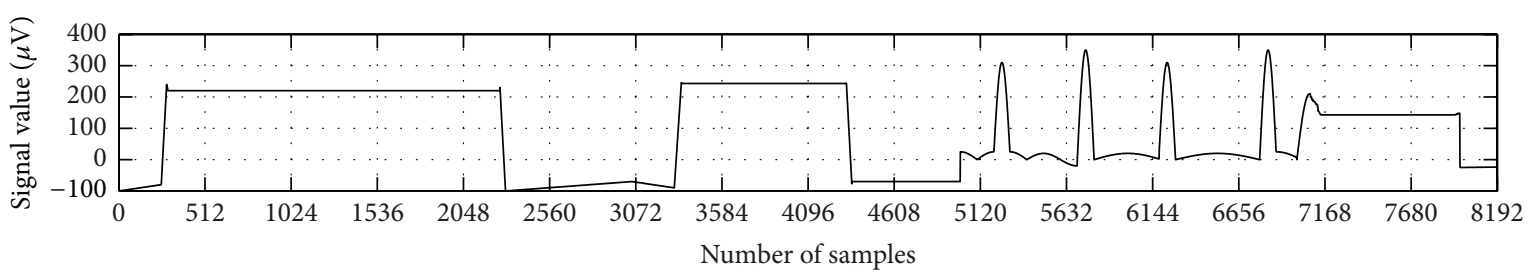

(a) Reference EOG signal

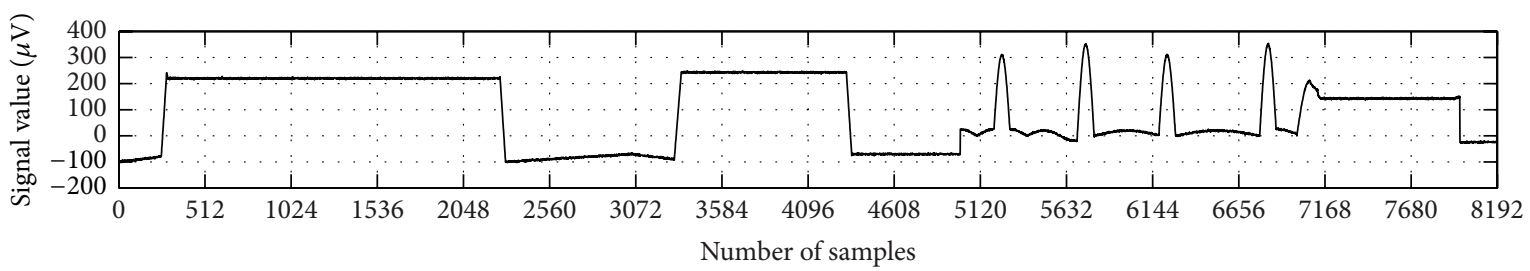

(b) EOG signal with noise power $5 \mathrm{~dB}$

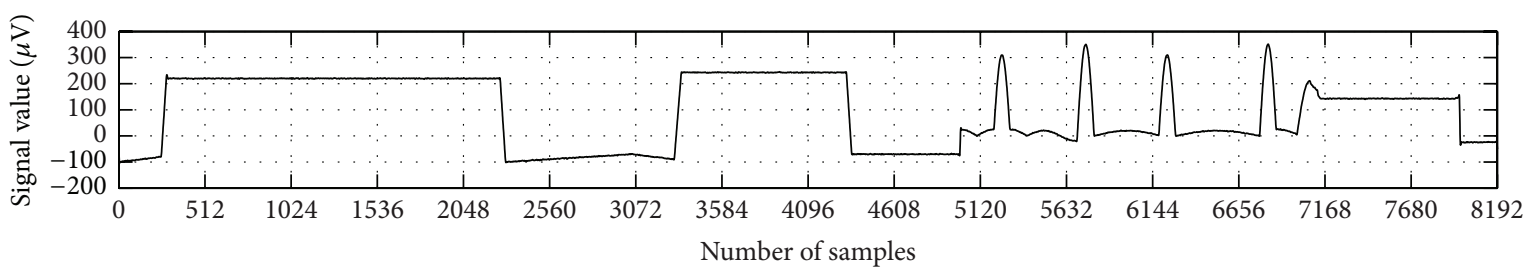

(c) Denoised-EOG signal with noise power $5 \mathrm{~dB}$

Figure 4: (a) Reference EOG signal, (b) EOG signal with noise power $5 \mathrm{~dB}$, and (c) denoised-EOG signal with noise power $5 \mathrm{~dB}$.

(ii) different equal segments of 8192 samples of noisy EOG signal $(1: 512,513: 1024,1025: 1536, \ldots)$. Here one segment is equal to 512 samples.

The RMSE values for each segment are calculated between the reference EOG signal and the denoised-EOG signal in both methods.
Further, the maximum, minimum, mean, and standard deviation values are also calculated from the obtained RMSE values.

Estimation of Root Mean Square Error (RMSE). Consider

$$
\operatorname{RMSE}=\sqrt{ } \frac{1}{N} \sum_{i=1}^{N}(x(i)-\bar{x}(i))^{2},
$$


TABLE 1: RMSE values obtained between reference EOG signal and denoised EOG signals by increasing segments approach using SWT technique.

\begin{tabular}{|c|c|c|c|c|c|c|}
\hline S. number & $\begin{array}{l}\text { Segment of the } \\
\text { signal (samples) }\end{array}$ & $\begin{array}{c}\text { EOG5 dB } \\
\text { SNR }=39.04 \mathrm{~dB} \\
\text { RMSE }(\mu \mathrm{V})\end{array}$ & $\begin{array}{c}\text { EOG10 dB } \\
\text { SNR }=33.92 \mathrm{~dB} \\
\text { RMSE }(\mu \mathrm{V})\end{array}$ & $\begin{array}{c}\text { EOG15 dB } \\
\text { SNR }=29.02 \mathrm{~dB} \\
\text { RMSE }(\mu \mathrm{V})\end{array}$ & $\begin{array}{c}\text { EOG20 dB } \\
\text { SNR }=24.12 \mathrm{~dB} \\
\text { RMSE }(\mu \mathrm{V})\end{array}$ & $\begin{array}{c}\text { EOG } 25 \mathrm{~dB} \\
\text { SNR }=19.01 \mathrm{~dB} \\
\text { RMSE }(\mu \mathrm{V})\end{array}$ \\
\hline 1 & $1: 512$ & 8.38 & 8.39 & 8.81 & 9.78 & 10.92 \\
\hline 2 & $1: 1024$ & 5.94 & 6.05 & 6.63 & 7.52 & 9.35 \\
\hline 3 & $1: 1536$ & 4.88 & 5.02 & 5.61 & 6.71 & 9.06 \\
\hline 4 & 1:2048 & 4.25 & 4.41 & 5.05 & 6.25 & 8.91 \\
\hline 5 & $1: 2560$ & 0.91 & 1.56 & 2.79 & 4.61 & 7.81 \\
\hline 6 & $1: 3072$ & 0.94 & 1.57 & 2.78 & 4.60 & 7.89 \\
\hline 7 & $1: 3584$ & 3.48 & 3.69 & 4.36 & 5.77 & 8.60 \\
\hline 8 & 1:4096 & 3.27 & 3.49 & 4.20 & 5.60 & 8.49 \\
\hline 9 & 1:4608 & 0.92 & 1.55 & 2.75 & 4.59 & 7.96 \\
\hline 10 & $1: 5120$ & 1.46 & 1.93 & 2.97 & 4.73 & 8.04 \\
\hline 11 & $1: 5632$ & 1.34 & 1.84 & 2.88 & 4.68 & 8.05 \\
\hline 12 & $1: 6144$ & 1.38 & 1.87 & 2.91 & 4.70 & 8.07 \\
\hline 13 & $1: 6656$ & 1.39 & 1.87 & 2.89 & 4.68 & 8.12 \\
\hline 14 & $1: 7168$ & 2.03 & 2.37 & 3.23 & 4.95 & 8.25 \\
\hline 15 & $1: 7680$ & 1.97 & 2.33 & 3.20 & 4.91 & 8.29 \\
\hline 16 & 1:8192 & 1.53 & 1.99 & 2.94 & 4.79 & 8.22 \\
\hline \multicolumn{2}{|c|}{ Maximum value } & 8.38 & 8.39 & 8.81 & 9.78 & 10.92 \\
\hline \multicolumn{2}{|c|}{ Minimum value } & 0.91 & 1.55 & 2.75 & 4.59 & 7.81 \\
\hline \multicolumn{2}{|c|}{ Mean $(\mu \mathrm{V})$} & 2.75 & 3.12 & 4.00 & 5.55 & 8.50 \\
\hline \multicolumn{2}{|c|}{ Standard deviation $(\mu \mathrm{V})$} & 2.15 & 1.97 & 1.74 & 1.43 & 0.78 \\
\hline
\end{tabular}

where $N$ is the length of the EOG signal, $x(i)$ is the reference EOG signal, and $\bar{x}(i)$ is the denoised-EOG signal.

\section{Results and Discussions}

Let us consider the denoising analysis for the increasing segments of the five noisy EOG signals EOG5 dB, EOG10 dB, EOG15 dB, EOG20 dB, and EOG25 dB. By denoising these noisy EOG signals with SWT technique, the maximum RMSE values obtained are between $8.38 \mu \mathrm{V}$ and $10.92 \mu \mathrm{V}$. All these maximum values obtained are for the 1:512 samples segment. These high values are due to the less concentration of the EOG signal as shown in Figure 4(b). The minimum RMSE values obtained are between $0.91 \mu \mathrm{V}$ and $7.81 \mu \mathrm{V}$. But the minimum RMSE values $4.59 \mu \mathrm{V}$ and $7.81 \mu \mathrm{V}$ obtained by denoising EOG20 dB and EOG $25 \mathrm{~dB}$ signals are comparatively higher values over the minimum RMSE values obtained by denoising EOG $5 \mathrm{~dB}$, EOG10 dB, and EOG15 dB signals. By denoising 16 segments in this method, the mean and standard deviations for the obtained RMSE values are found to be $(2.75 \mu \mathrm{V}$ and $2.15 \mu \mathrm{V}, 3.12 \mu \mathrm{V}$ and $1.97 \mu \mathrm{V}$, and $4.00 \mu \mathrm{V}$ and $1.74 \mu \mathrm{V}$ ) for EOG5 $\mathrm{dB}$, EOG10 dB, and EOG15 dB signals. From Table 1, these values are considerably better when compared with EOG $20 \mathrm{~dB}$ and EOG $25 \mathrm{~dB}$ signals $(5.55 \mu \mathrm{V}$ and $1.43 \mu \mathrm{V}$, and $8.50 \mu \mathrm{V}$ and $0.78 \mu \mathrm{V}$ ).

Again by denoising all the five noisy EOG signals with RLS adaptive filtering technique, the maximum RMSE values obtained are between $35.92 \mu \mathrm{V}$ and $36.49 \mu \mathrm{V}$. All these maximum values obtained are for the $1: 512$ samples segment. These high values are due to the less concentration of the EOG signal as already stated. The minimum RMSE values obtained are between $17.97 \mu \mathrm{V}$ and $18.38 \mu \mathrm{V}$ as given in Table 2. But these statistical values are very large when compared with the values obtained by SWT technique as given in Table 1 .

From the analysis of the different equal segments of the considered noisy EOG signals with SWT technique, the maximum RMSE values obtained are between $8.38 \mu \mathrm{V}$ and $11.73 \mu \mathrm{V}$ in the segment of 1:512 samples except for the maximum RMSE value $11.73 \mu \mathrm{V}$ obtained for the segment of 4097:4068 samples. This is negligible when compared with RMSE value $10.92 \mu \mathrm{V}$ obtained for the segment of 1:512 samples. The minimum RMSE values are between $0.75 \mu \mathrm{V}$ and $2.44 \mu \mathrm{V}$, respectively, for EOG5 $\mathrm{dB}$, EOG10 dB, and EOG15 dB signals which are very less when compared with $4.16 \mu \mathrm{V}$ and $7.28 \mu \mathrm{V}$ RMSE values obtained by denoising EOG20 dB and EOG25 dB signals. For EOG5 dB, EOG10 dB, and EOG15 $\mathrm{dB}$ signals analysis, the mean and standard deviations are found to be $3.35 \mu \mathrm{V}$ and $3.21 \mu \mathrm{V}, 3.77 \mu \mathrm{V}$ and $2.97 \mu \mathrm{V}$, and $3.99 \mu \mathrm{V}$ and $2.61 \mu \mathrm{V}$. These values are considerably better when compared with EOG $20 \mathrm{~dB}$ and EOG $25 \mathrm{~dB}$ signals which are $6.11 \mu \mathrm{V}$ and $2.23 \mu \mathrm{V}$, and $9.17 \mu \mathrm{V}$ and $1.44 \mu \mathrm{V}$ as given in Table 3.

For RLS adaptive filtering technique, the maximum RMSE values obtained are between $49.52 \mu \mathrm{V}$ and $50.60 \mu \mathrm{V}$. The minimum RMSE values are between $13.97 \mu \mathrm{V}$ and $14.45 \mu \mathrm{V}$, respectively. The mean and standard deviations which are obtained are extremely large when compared with the values obtained by SWT technique as given in Tables 3 and 4 .

The denoised-EOG5 $\mathrm{dB}$ (Figure 4(c)) and denoisedEOG20 dB (Figure 5(c)) signals with SWT technique are 
TABLE 2: RMSE values obtained between reference EOG signal and denoised EOG signals by increasing segments approach using RLS adaptive filtering technique.

\begin{tabular}{|c|c|c|c|c|c|c|}
\hline S. number & $\begin{array}{l}\text { Segment of the } \\
\text { signal (samples) }\end{array}$ & $\begin{array}{c}\text { EOG5 dB } \\
\text { SNR }=39.04 \mathrm{~dB} \\
\text { RMSE }(\mu \mathrm{V})\end{array}$ & $\begin{array}{c}\text { EOG10 dB } \\
\text { SNR }=33.92 \mathrm{~dB} \\
\text { RMSE }(\mu \mathrm{V})\end{array}$ & $\begin{array}{c}\text { EOG15 dB } \\
\text { SNR }=29.02 \mathrm{~dB} \\
\text { RMSE }(\mu \mathrm{V})\end{array}$ & $\begin{array}{c}\text { EOG20 dB } \\
\text { SNR }=24.12 \mathrm{~dB} \\
\text { RMSE }(\mu \mathrm{V})\end{array}$ & $\begin{array}{c}\text { EOG25 dB } \\
\text { SNR }=19.01 \mathrm{~dB} \\
\text { RMSE }(\mu \mathrm{V})\end{array}$ \\
\hline 1 & $1: 512$ & 36.12 & 35.92 & 36.42 & 36.49 & 36.20 \\
\hline 2 & $1: 1024$ & 25.54 & 25.40 & 25.76 & 25.84 & 25.71 \\
\hline 3 & $1: 1536$ & 20.85 & 20.75 & 21.05 & 21.13 & 21.12 \\
\hline 4 & $1: 2048$ & 18.06 & 17.97 & 18.24 & 18.33 & 18.38 \\
\hline 5 & $1: 2560$ & 22.00 & 21.93 & 22.16 & 22.18 & 22.15 \\
\hline 6 & $1: 3072$ & 22.09 & 20.03 & 20.23 & 20.26 & 20.28 \\
\hline 7 & $1: 3584$ & 22.05 & 21.99 & 22.12 & 22.19 & 22.11 \\
\hline 8 & 1:4096 & 20.63 & 20.57 & 20.69 & 20.77 & 20.72 \\
\hline 9 & 1:4608 & 22.30 & 22.32 & 22.40 & 22.57 & 22.51 \\
\hline 10 & $1: 5120$ & 21.63 & 21.65 & 21.74 & 21.88 & 21.86 \\
\hline 11 & $1: 5632$ & 23.80 & 23.81 & 23.94 & 24.11 & 23.98 \\
\hline 12 & $1: 6144$ & 26.69 & 26.69 & 26.83 & 27.04 & 26.87 \\
\hline 13 & $1: 6656$ & 28.13 & 28.15 & 28.22 & 28.50 & 28.31 \\
\hline 14 & $1: 7168$ & 30.08 & 30.13 & 30.21 & 30.44 & 30.32 \\
\hline 15 & $1: 7680$ & 29.06 & 29.10 & 29.19 & 29.41 & 29.31 \\
\hline 16 & 1:8192 & 28.87 & 28.91 & 28.98 & 29.16 & 29.10 \\
\hline \multicolumn{2}{|c|}{ Maximum value } & 36.12 & 35.92 & 36.42 & 36.49 & 36.20 \\
\hline \multicolumn{2}{|c|}{ Minimum value } & 18.06 & 17.97 & 18.24 & 18.33 & 18.38 \\
\hline \multicolumn{2}{|c|}{ Mean $(\mu \mathrm{V})$} & 24.87 & 24.71 & 24.89 & 25.02 & 24.93 \\
\hline \multicolumn{2}{|c|}{ Standard deviation $(\mu \mathrm{V})$} & 4.65 & 4.76 & 4.78 & 4.81 & 4.74 \\
\hline
\end{tabular}

TABLE 3: RMSE values obtained between reference EOG signal and denoised EOG signals by different equal segments approach using SWT technique.

\begin{tabular}{|c|c|c|c|c|c|c|}
\hline S. number & $\begin{array}{l}\text { Segment of the } \\
\text { signal (samples) }\end{array}$ & $\begin{array}{c}\text { EOG5 dB } \\
\text { SNR }=39.04 \mathrm{~dB} \\
\text { RMSE }(\mu \mathrm{V})\end{array}$ & $\begin{array}{c}\text { EOG10 dB } \\
\text { SNR }=33.92 \mathrm{~dB} \\
\text { RMSE }(\mu \mathrm{V})\end{array}$ & $\begin{array}{c}\text { EOG15 dB } \\
\text { SNR }=29.02 \mathrm{~dB} \\
\text { RMSE }(\mu \mathrm{V})\end{array}$ & $\begin{array}{c}\text { EOG20 dB } \\
\text { SNR }=24.12 \mathrm{~dB} \\
\text { RMSE }(\mu \mathrm{V})\end{array}$ & $\begin{array}{c}\text { EOG25 dB } \\
\text { SNR }=19.01 \mathrm{~dB} \\
\text { RMSE }(\mu \mathrm{V})\end{array}$ \\
\hline 1 & $1: 512$ & 8.38 & 8.39 & 8.81 & 9.78 & 10.92 \\
\hline 2 & $513: 1024$ & 0.75 & 1.56 & 3.06 & 4.34 & 7.28 \\
\hline 3 & $1025: 1536$ & 0.88 & 1.57 & 2.82 & 4.50 & 7.93 \\
\hline 4 & $1537: 2048$ & 0.82 & 1.46 & 2.47 & 4.66 & 8.35 \\
\hline 5 & 2049:2560 & 8.05 & 8.18 & 8.50 & 9.52 & 11.15 \\
\hline 6 & 2561:3072 & 0.96 & 1.54 & 2.68 & 4.58 & 8.28 \\
\hline 7 & 3073:3584 & 8.21 & 8.32 & 8.66 & 9.49 & 11.54 \\
\hline 8 & $3585: 4096$ & 0.81 & 1.39 & 2.71 & 4.32 & 7.89 \\
\hline 9 & 4097:4608 & 8.18 & 8.27 & 8.55 & 9.28 & 11.73 \\
\hline 10 & 4609:5120 & 3.27 & 3.55 & 4.10 & 5.46 & 8.70 \\
\hline 11 & $5121: 5632$ & 0.95 & 1.59 & 2.44 & 4.58 & 8.24 \\
\hline 12 & 5633:6144 & 1.05 & 1.62 & 2.87 & 4.79 & 8.27 \\
\hline 13 & $6145: 6656$ & 1.06 & 1.59 & 2.49 & 4.16 & 8.59 \\
\hline 14 & $6657: 7168$ & 3.53 & 3.76 & 4.16 & 6.10 & 8.81 \\
\hline 15 & $7169: 7680$ & 0.84 & 1.49 & 2.61 & 4.31 & 8.64 \\
\hline 16 & 7681:8192 & 5.89 & 6.09 & 6.36 & 7.84 & 10.31 \\
\hline \multicolumn{2}{|c|}{ Maximum value } & 8.38 & 8.39 & 8.81 & 9.78 & 11.73 \\
\hline \multicolumn{2}{|c|}{ Minimum value } & 0.75 & 1.39 & 2.44 & 4.16 & 7.28 \\
\hline \multicolumn{2}{|c|}{ Mean $(\mu \mathrm{V})$} & 3.35 & 3.77 & 3.99 & 6.11 & 9.17 \\
\hline \multicolumn{2}{|c|}{ Standard deviation $(\mu \mathrm{V})$} & 3.21 & 2.97 & 2.61 & 2.23 & 1.44 \\
\hline
\end{tabular}


TABLE 4: RMSE values obtained between reference EOG signal and denoised EOG signals by different equal segments approach using RLS adaptive filtering technique.

\begin{tabular}{|c|c|c|c|c|c|c|}
\hline S. number & $\begin{array}{l}\text { Segment of the } \\
\text { signal (samples) }\end{array}$ & $\begin{array}{c}\text { EOG5 dB } \\
\text { SNR }=39.04 \mathrm{~dB} \\
\text { RMSE }(\mu \mathrm{V})\end{array}$ & $\begin{array}{c}\text { EOG10 dB } \\
\text { SNR }=33.92 \mathrm{~dB} \\
\text { RMSE }(\mu \mathrm{V})\end{array}$ & $\begin{array}{c}\text { EOG15 dB } \\
\text { SNR }=29.02 \mathrm{~dB} \\
\text { RMSE }(\mu \mathrm{V})\end{array}$ & $\begin{array}{c}\text { EOG20 dB } \\
\text { SNR }=24.12 \mathrm{~dB} \\
\text { RMSE }(\mu \mathrm{V})\end{array}$ & $\begin{array}{c}\text { EOG25 dB } \\
\text { SNR }=19.01 \mathrm{~dB} \\
\text { RMSE }(\mu \mathrm{V})\end{array}$ \\
\hline 2 & $513: 1024$ & 34.47 & 34.48 & 34.39 & 34.60 & 34.45 \\
\hline 3 & 1025:1536 & 34.45 & 34.39 & 34.35 & 34.60 & 34.65 \\
\hline 4 & $1537: 2048$ & 34.42 & 34.43 & 34.49 & 34.38 & 34.60 \\
\hline 5 & 2049:2560 & 47.94 & 47.92 & 48.07 & 48.10 & 47.87 \\
\hline 6 & $2561: 3072$ & 13.97 & 13.99 & 14.07 & 14.00 & 14.45 \\
\hline 7 & 3073:3584 & 24.27 & 33.29 & 33.09 & 33.37 & 33.01 \\
\hline 8 & $3585: 4096$ & 38.03 & 38.03 & 38.08 & 37.97 & 38.31 \\
\hline 9 & 4097:4608 & 50.17 & 50.43 & 50.28 & 35.88 & 50.60 \\
\hline 10 & 4609:5120 & 18.06 & 18.04 & 18.24 & 18.01 & 18.45 \\
\hline 11 & $5121: 5632$ & 39.40 & 39.41 & 39.75 & 40.14 & 39.33 \\
\hline 12 & 5633:6144 & 48.21 & 48.09 & 48.39 & 48.80 & 48.37 \\
\hline 13 & $6145: 6656$ & 41.69 & 41.89 & 41.43 & 41.85 & 41.92 \\
\hline 14 & $6657: 7168$ & 48.86 & 19.08 & 49.26 & 49.52 & 49.54 \\
\hline 15 & $7169: 7680$ & 22.41 & 22.33 & 22.40 & 22.59 & 23.02 \\
\hline 16 & 7681:8192 & 34.11 & 34.12 & 34.10 & 33.49 & 33.95 \\
\hline \multicolumn{2}{|c|}{ Maximum value } & 50.17 & 50.43 & 50.28 & 49.52 & 50.60 \\
\hline \multicolumn{2}{|c|}{ Minimum value } & 13.97 & 13.99 & 14.07 & 14.00 & 14.45 \\
\hline \multicolumn{2}{|c|}{ Mean $(\mu \mathrm{V})$} & 35.36 & 34.00 & 36.02 & 35.15 & 36.17 \\
\hline \multicolumn{2}{|c|}{ Standard deviation $(\mu \mathrm{V})$} & 11.46 & 11.29 & 11.11 & 10.51 & 11.03 \\
\hline
\end{tabular}

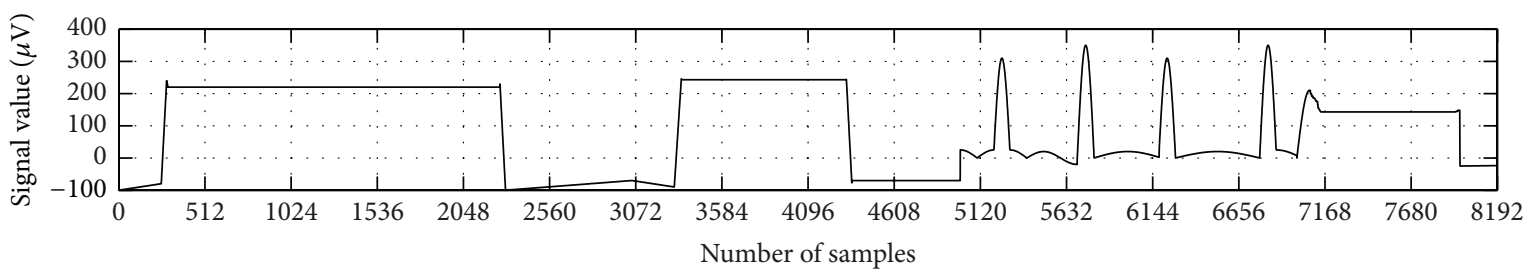

(a) Reference EOG signal

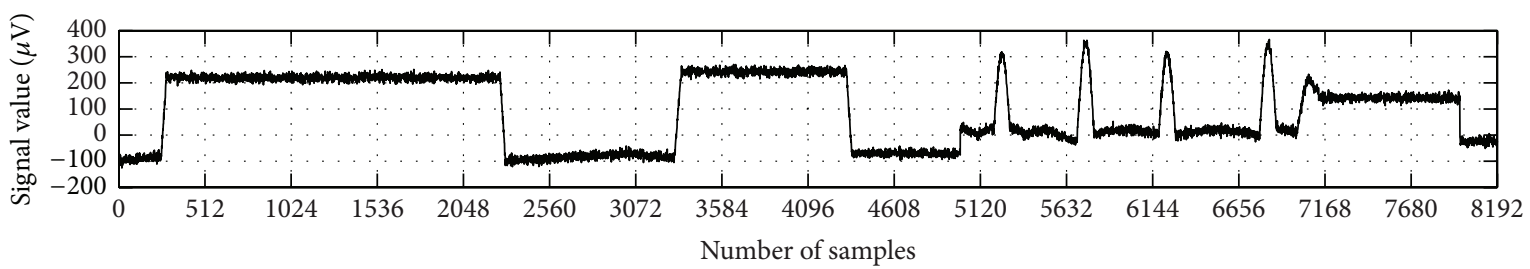

(b) EOG signal with noise power $20 \mathrm{~dB}$

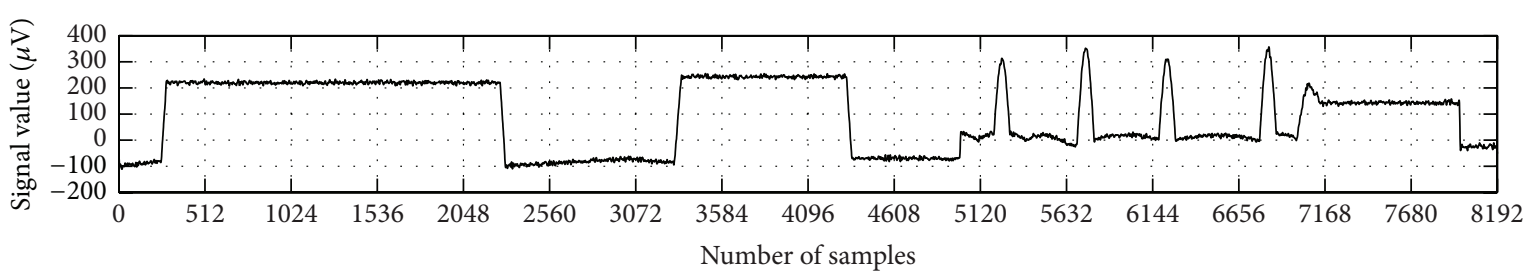

(c) Denoised-EOG signal with noise power $20 \mathrm{~dB}$

FIGURE 5: (a) Reference EOG signal, (b) EOG signal with noise power $20 \mathrm{~dB}$, and (c) denoised-EOG signal with noise power $20 \mathrm{~dB}$. 
shown in Figures 4 and 5 along with reference EOG signals (Figures 4(a) and 5(a)).

\section{Conclusion}

The present study deals with the optimization of SWT technique in denoising the EOG signals with respect to different levels of noise power. The findings suggest that SWT technique is a suitable technique to denoise the EOG signal with noise powers up to $15 \mathrm{~dB}$ in terms of RMSE values. Any noise power more than the $15 \mathrm{~dB}$ will not give us quality output. The results obtained are remarkable with very low RMSE values at simulation level for considerable noise powers. Even when the results are compared with RLS adaptive filtering technique analysis, which was proven to be the best adaptive filter algorithm for EOG signal processing [3], the SWT technique yielded better results. Thus it may be concluded that, by the proposed method of denoising, the quality EOG signal can be useful in the field of medicine for effective diagnosis of various neurological and eye disorders.

\section{Conflict of Interests}

The author declares that there is no conflict of interests regarding the publication of this paper.

\section{Acknowledgment}

The author is very thankful for the support provided by the Department of Physics and Nanotechnology, SRM University, Kattankulathur, Tamil Nadu, India.

\section{References}

[1] S. R. Choudhury, S. Venkataramanan, H. B. Nemade, and J. S. Sahambi, "Design and development of a novel EOG biopotential amplifier," International Journal of Business and Emerging Markets, vol. 7, no. 1, pp. 270-274, 2005.

[2] M. Kaur, B. Singh, J. S. Ubhi, and S. Rani, "Digital filteration of ECG signals for removal of baseline drift," in Proceedings of the International Conference on Telecommunication Technology and Applications (CSIT '11), vol. 5, pp. 105-109, IACSIT Press, Singapore, 2011.

[3] A. Naga Rajesh, S. Chandralingam, T. Anjaneyulu, and K. Satyanarayana, "Performance evaluation of adaptive filter algorithms for EOG signal processing," International Journal of Systems, Algorithms and Applications, vol. 2, pp. 14-18, 2012.

[4] R. A. Naga, S. Chandralingam, T. Anjaneyulu, and K. Satyanarayana, "Denoising EOG signal using stationary wavelet transform," Measurement Science Review, vol. 12, no. 2, pp. 46$51,2012$.

[5] S. Mala and K. Latha, "Feature selection in classification of eye movements using electrooculography for activity recognition," Computational and Mathematical Methods in Medicine, vol. 2014, Article ID 713818, 9 pages, 2014.

[6] M. Malini and K. SubbaRao, "Analysis of EOG signal using haar wavelet," in Proceedings of the International Symposium on Devices MEMS, Intelligent Systems \& Communication (ISDMISC'11), pp. 28-31, International Journal of Computer Applications(IJCA), 2011.
[7] M. S. Reddy, B. Narasimha, E. Suresh, and K. S. Rao, "Analysis of EOG signals using wavelet transform for detecting eye blinks," in Proceedings of the International Conference on Wireless Communications and Signal Processing (WCSP '10), pp. 1-4, IEEE, Suzhou, China, October 2010.

[8] D. R. Mali, S. M. Khadtare, and U. L. Bombale, "Removal of $50 \mathrm{~Hz}$ PLI using discrete wavelet transform for quality diagnosis of biomedical ECG signal," International Journal of Computer Applications, vol. 23, no. 7, pp. 1-6, 2011.

[9] V. N. P. Raj and T. Venkateswarlu, "ECG signal denoising using undecimated wavelet transform," in Proceedings of the $3 \mathrm{rd}$ International Conference on Electronics Computer Technology (ICECT '11), pp. 94-98, IEEE, Kanyakumari, India, April 2011.

[10] V. Krishnaveni, S. Jayaraman, S. Aravind, V. Hariharasudhan, and K. Ramadoss, "Automatic identification and removal of ocular artifacts from EEG using wavelet transform," Measurement Science Review, vol. 6, no. 4, pp. 45-57, 2006.

[11] M. Kania, M. Fereniec, and R. Maniewski, "Wavelet denoising for multi-lead high resolution ECG signals," Measurement Science Review, vol. 7, no. 4, pp. 30-33, 2007.

[12] M. C. E. Rosas-Orea, M. Hernandez-Diaz, V. Alarcon-Aquino, and L. G. Guerrero-Ojeda, "A comparative simulation study of wavelet based denoising algorithms," in Proceedings of the 15th International Conference on Electronics, Communications and Computers (CONIELECOMP '05), pp. 125-130, IEEE, March 2005.

[13] P. He, G. Wilson, and C. Russell, "Removal of ocular artifacts from electro-encephalogram by adaptive filtering," Medical and Biological Engineering \& Computing, vol. 42, no. 3, pp. 407-412, 2004.

[14] J. A. Apolinário Jr., QRD-RLS Adaptive Filtering, Springer, New York, NY, USA, 2009. 

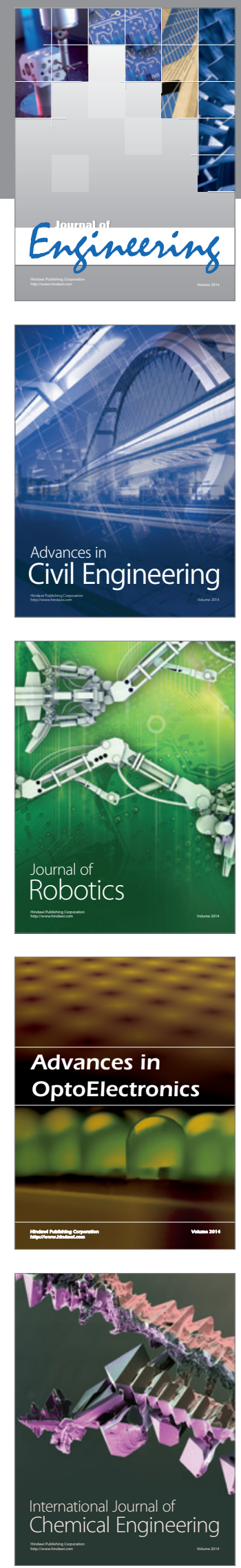

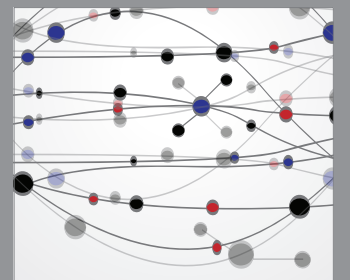

The Scientific World Journal
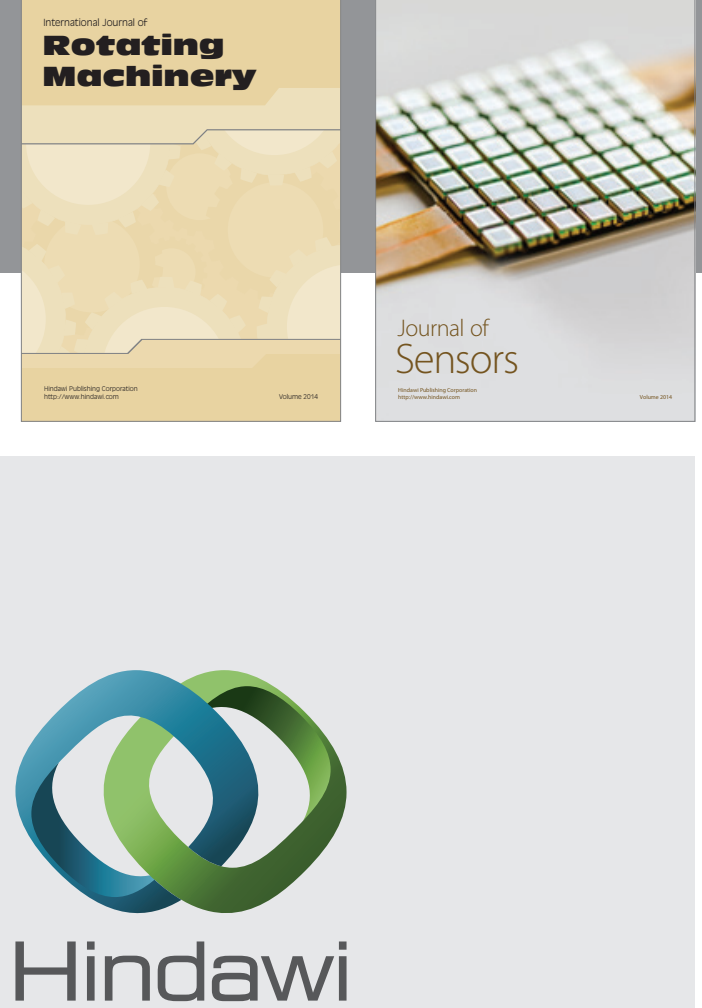

Submit your manuscripts at http://www.hindawi.com
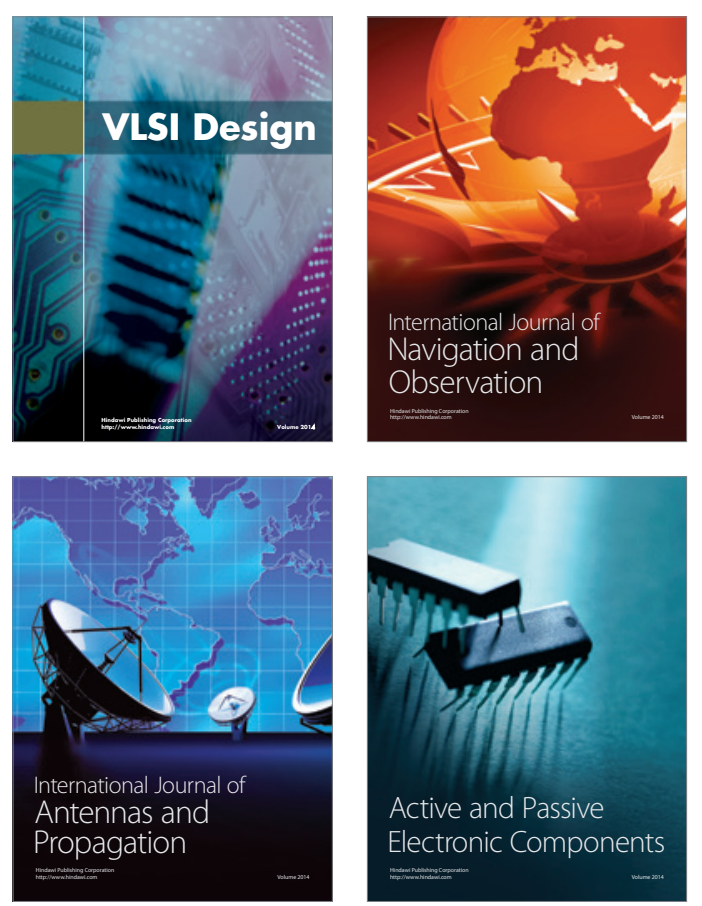
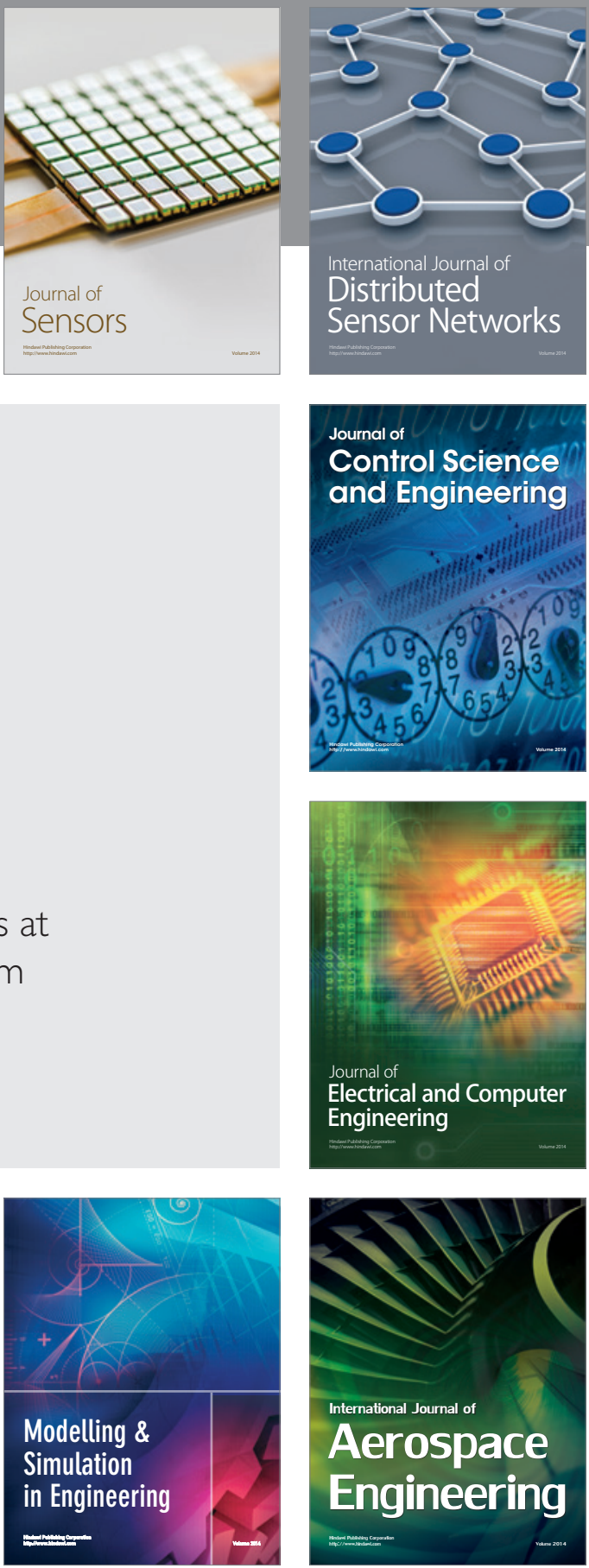

Journal of

Control Science

and Engineering
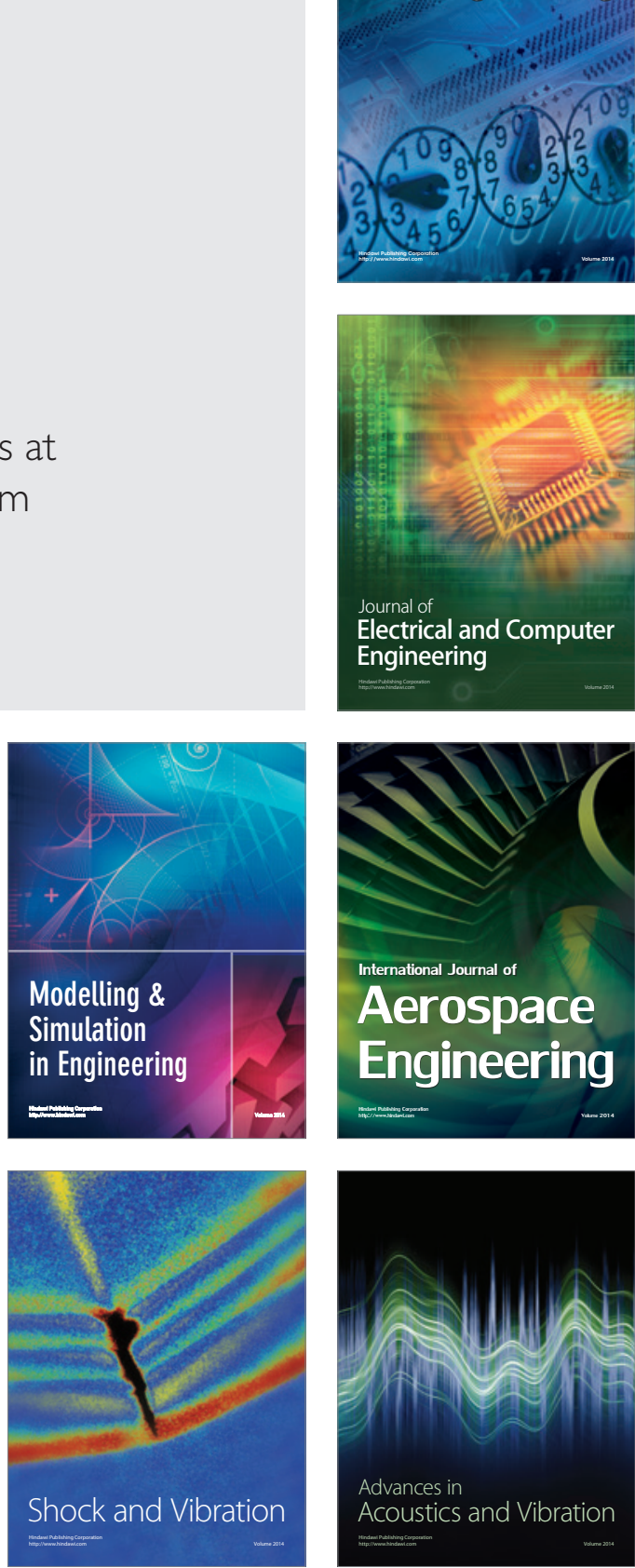